\title{
COMPLEJIDADES DEL PERIODO INTERINO DE UN CONTRATO DE COMPRAVENTA DE ACCIONES EN EL MARCO DEL COVID-19
}

\author{
Alexandra Arizmendi de Romaña \\ Universidad de Lima, Lima, Perú
}

Recibido: 17/8/2020 - Aprobado: 24/8/2020

doi: https://doi.org/10.26439/iusetpraxis2020.n50-51.5040

\begin{abstract}
RESUMEN. El presente artículo aborda aquellas situaciones contractuales que quedaron fuera del pacto contractual ante una situación no prevista como la pandemia ocasionada por el brote del COVID-19 y el consecuente estado de emergencia promulgado en el Perú. El análisis se efectúa en el marco de un contrato de compraventa de bien mueble, en que el activo en venta representa un activo subyacente cuyo valor depende de su buena preservación durante la pandemia: las acciones de una sociedad en marcha. Así pues, realiza un repaso de las figuras disponibles en el derecho civil para encaminar las complejidades que presenta un contrato de compraventa de acciones durante el periodo interino entre la firma del contrato y la fecha de cierre.
\end{abstract}

PALABRAS CLAVE: contratos de compraventa de acciones / activo subyacente / periodo interino / negocio en marcha / apalancamiento / exención

\section{COMPLEXITIES OF THE INTERIM PERIOD OF A STOCK PURCHASE AGREEMENT WITHIN THE FRAMEWORK OF COVID-19}

ABSTRACT. This paper addresses those contractual situations that were left out of the contractual agreement, in the face of unforeseen circumstances such as the pandemic caused by the COVID-19 outbreak and the resulting state of emergency declared in Peru. The analysis is carried out within the framework of a stock purchase agreement, where the asset for sale consists of an underlying asset whose value depends on its good state of preservation during the pandemic: the shares of an operating company. Thus, this article reviews those tools available in civil law to address the complexities presented by a stock purchase agreement during the interim period between its execution and closing date.

KEYWORDS: stock purchase agreements / underlying asset / interim period / operating corporation / leverage / waiver 


\section{INTRODUCCIÓN}

El presente artículo se basa en la ponencia realizada en el webinario internacional El derecho civil ante el COVID-19. En dicha ponencia, se tomó como punto de referencia un caso hipotético (en adelante, el caso de estudio) para el desarrollo de la potencial problemática que se podría presentar en una transacción de compraventa de acciones cuando estos contratos se negocian en momentos de crisis, como la pandemia generada por el COVID-19. El análisis de este caso servirá para evaluar las herramientas que se encuentran en nuestro ordenamiento jurídico y en el derecho comparado, para observar cómo podemos actuar ante situaciones imprevistas como la que estamos viviendo ahora a causa del coronavirus.

\section{EL CONTRATO DE COMPRAVENTA DE ACCIONES}

El caso de estudio es uno sencillo en el marco de un contrato de compraventa de acciones (en adelante, el contrato). A diferencia de un contrato de compraventa de cualquier otro bien (una casa, un automóvil, cualquier otro mueble, etcétera), en un contrato de compra de acciones el bien materia de venta (las acciones) representa un activo subyacente (una compañía). El valor de las acciones en venta se encuentra íntimamente ligado al valor de la compañía subyacente (entendida como empresa en marcha, conjunto de activos, obligaciones, derechos, etcétera). Entonces, al tener ese componente distinto, el mundo del derecho civil, que regula el contrato de compraventa, encuentra una intersección con el mundo del derecho corporativo, que regula el activo subyacente. En ese sentido, en el contexto general de la operación de compraventa de acciones, los intereses de las partes contractuales de la compraventa (comprador y vendedor) estarán íntimamente ligados al valor de la compañía entendida como un negocio en marcha al momento en que se negocia, firma y cierra el contrato de compraventa. En tal sentido, ese valor puede variar en el tiempo, incluyendo el periodo en el que se desarrolla la operación de compraventa.

A continuación, se presenta una línea de tiempo que muestra las distintas etapas de un contrato de compraventa de acciones con la particularidad de que, en nuestro caso de estudio, la firma del contrato (en adelante, la fecha de firma) será en una fecha distinta a la del cierre de la operación (en adelante, la fecha de cierre). 


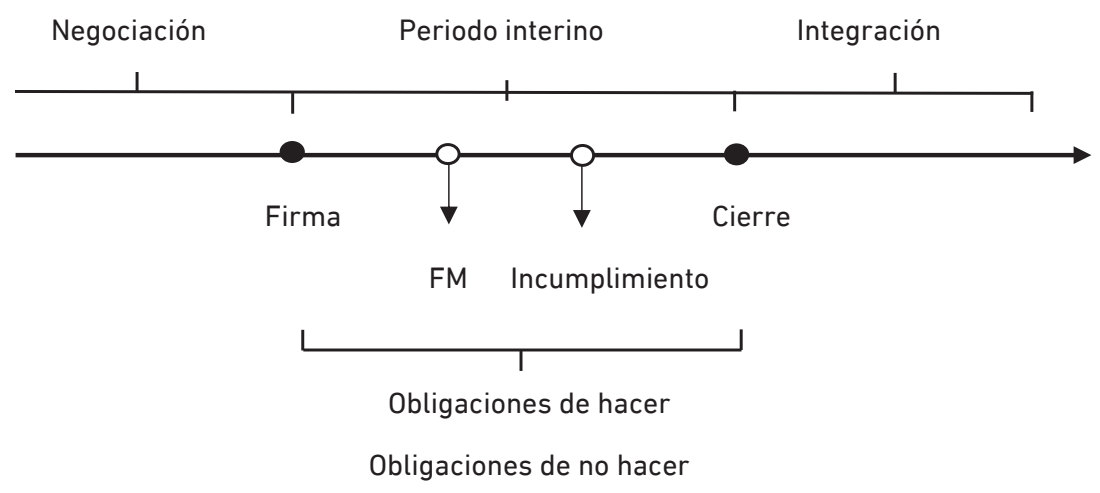

Elaboración propia

En el caso de estudio, en la fecha de firma se suscribe el contrato, con lo que se obliga las partes a transferir la titularidad de las acciones y la contraprestación en la fecha de cierre, siempre y cuando se verifiquen las condiciones precedentes acordadas por las partes. En el periodo interino, cada una de las partes se encargará de realizar los actos necesarios para cumplir con las condiciones precedentes a la fecha de cierre que se encuentran a su cargo.

En ese periodo interino, se desata la situación de la pandemia a consecuencia del COVID-19. Como todos hemos experimentado, las reacciones de los diversos países frente a esta pandemia han sido distintas, y se han dictado múltiples medidas de seguridad, salud y economía. Concretamente, en el Perú se emitió el Decreto Supremo 044-2020-PCM, que declaró el estado de emergencia nacional (en adelante, el estado de emergencia), el cual ha sido prorrogado y modificado por disposiciones subsecuentes. Entre las medidas dictadas por el Gobierno peruano, se dispuso la inmovilidad social obligatoria y, en consecuencia, muchas empresas no han podido operar durante meses. Adicionalmente, se determinaron normas destinadas a la activación progresiva de la economía, así como exigencias para la implementación de protocolos sanitarios.

Es práctica regular que este periodo interino se encuentre bastante regulado contractualmente en los contratos de compraventa de acciones mediante: i) obligaciones de hacer, como, por ejemplo, operar el día a día del negocio de la misma forma en que se ha venido operando en el último año; así como ii) obligaciones de no hacer, como, por ejemplo, abstenerse de solicitar deuda adicional, abstenerse de disponer de activos importantes para el negocio de la compañía, abstenerse de realizar inversiones en capex, etcétera.

En el contexto del COVID-19 y el estado de emergencia, hemos observado cómo en muy pocas semanas la gran mayoría de las empresas peruanas se han visto fuertemente limitadas en la operación de sus negocios. Muchas no han podido operar por semanas, lo 
cual ha conllevado la inejecución de sus obligaciones contractuales y, al mismo tiempo, se han visto perjudicadas por la inejecución de obligaciones de sus proveedores. Se han tenido que activar cláusulas de fuerza mayor, retardos, periodos de gracia y renegociaciones de acuerdos. El Gobierno les exige nuevas obligaciones a las empresas, como la implementación de protocolos sanitarios, restricciones en el reparto de sus productos, limitaciones de aforo, entre otros aspectos, que implican una inversión no prevista en su presupuesto. Asimismo, se produjo reducción de clientela, despido del personal y cierre de operaciones. En general, el mercado ha sido fuertemente impactado por esta paralización y a las empresas no les quedó otra opción que ser flexibles para reaccionar rápidamente a la nueva realidad y conseguir adaptarse para poder sobrevivir.

Resulta claro que la pandemia y el estado de emergencia constituyen una situación no imputable a las partes contratantes. Entonces, en el caso de estudio, la compañía se encuentra en un escenario de crisis y con riesgo de insolvencia. Cabe recordar que actualmente, durante el periodo interino, la compañía aún se encuentra en manos del vendedor y depende de este realizar los actos destinados a preservar la existencia y el valor de la compañía. De lo contrario, el valor del activo subyacente del contrato se perderá, lo cual perjudicará tanto al comprador como al vendedor. Sin embargo, al ser los contratos de compraventa tan variados en sus estructuras y como resultados propios de los tipos de industria de la compañía que es objetivo de la transacción, así como de los intereses de las partes que se encuentran en negociación, la situación de salvaguarda del valor no se resuelve tan fácilmente. Es aquí donde surge lo que denominamos "el dilema del vendedor".

\section{EL DILEMA DEL VENDEDOR: CUMPLIMIENTO CONTRACTUAL}

El dilema en el que se encuentra el vendedor consiste en debatirse entre: i) cumplir con las obligaciones de no hacer que se han establecido a su cargo en el contrato y, en consecuencia, no tomar acción frente a la crisis para salvaguardar el valor de la compañía, o ii) incumplir su obligación contractual de no hacer y tomar acciones para salvaguardar el valor de la compañía a pesar de que dichas acciones se encuentran expresamente restringidas por el contrato.

En el primer supuesto, en caso de que el vendedor cumpla su obligación contractual y efectivamente no haga nada frente a la crisis en la que se encuentra la compañía, dicho vendedor estará obligado a presenciar cómo su compañía se va en caída libre mientras él se queda de brazos cruzados o, más bien, contractualmente atado de manos. En ese caso, la compañía se estará viendo afectada exponencialmente conforme vaya pasando más tiempo en el contexto de la crisis sin un accionista a cargo que tome acciones para mitigar los perjuicios que se han producido en el negocio. Tengamos en cuenta que, mientras la compañía se encuentra afectada, también se perjudican sus stakeholders: 
trabajadores, acreedores, proveedores, etcétera. Adicionalmente, se genera un perjuicio potencial para el comprador en vista de que el activo subyacente del bien que va a adquirir por la operación de compraventa en la fecha de cierre habrá perdido su valor.

Por otro lado, la segunda opción que tiene el vendedor consiste en incumplir el contrato, pero tomar acciones para salvar la compañía y preservar el valor del negocio. Entonces, el vendedor podría, por ejemplo, acceder a los préstamos que ha facilitado el Gobierno para retomar operaciones; en consecuencia, el vendedor endeuda la compañía e incumple su obligación de no tomar deuda adicional en el periodo interino. Del mismo modo, el vendedor podría realizar una inversión para comprar activos destinados a cumplir con los protocolos dictados por el Gobierno para poder empezar a operar, o el vendedor podría vender una línea de negocio o maquinaria importante de la compañía para salvar el resto de las líneas de negocio de dicha compañía.

De la situación descrita, pareciera que no hay mucho que pensar, y que salvar la compañía sería la decisión adecuada a tomar en una situación como la que presenta el caso de estudio, ya que es la opción que, en principio, beneficia a todas las partes involucradas: la compañía, sus stakeholders, el vendedor e incluso el comprador. No obstante, antes de llegar a conclusiones anticipadas, revisemos la postura en la que se puede encontrar el comprador.

Las alternativas que maneja el comprador pueden ser decisiones válidas de negocio y estar pensadas en el interés de la compañía en general; sin embargo, el comprador puede válidamente poseer intereses muy particulares en la compañía, los cuales determinan su decisión de compra e incluso la valorización que ha efectuado a la compañía. Estos factores no necesariamente van a coincidir con las variables que el vendedor utiliza para darle valor a la compañía. Es así como, por ejemplo, el comprador puede tener interés particular en la compañía únicamente por una de sus líneas de negocio, y justamente esa línea es la que el vendedor desprende como una de sus medidas de salvaguarda ante la crisis. Otro ejemplo es que al comprador solo le sea económicamente eficiente adquirir una compañía con cierto nivel de apalancamiento, pero una vez que el vendedor toma la deuda nueva como medida de salvaguarda la ratio de apalancamiento cambia de tal forma que al comprador ya no le resulta económicamente eficiente la operación. Las medidas de salvaguarda del vendedor, si bien se encuentran destinadas a salvar el activo subyacente, al mismo tiempo pueden importar un cambio sustancial en las variables de la transacción y ocasionar que la operación genere menos sinergias u oportunidades distintas a las calculadas inicialmente por el comprador y, en consecuencia, baje el retorno esperado.

Un tema adicional a tener en cuenta que normalmente también se halla presente en este tipo de contratos son las denominadas cláusulas MAC (material adverse change) y MAE (material adverse effect), las cuales regulan circunstancias sustancialmente 
adversas. Precisamente estas cláusulas son mecanismos de salida del contrato a favor del comprador ante la ocurrencia de eventos que produzcan cambios o efectos sustancialmente adversos en el negocio de la compañía. La definición de estos eventos puede variar de contrato a contrato, pero en nuestro caso de estudio podría configurarse como efecto materialmente adverso la disminución de flujos de la compañía de una manera no prevista y radicalmente distinta al ejercicio anterior.

Estas son cláusulas estándar en los contratos de compraventa de acciones. Teniendo en cuenta esta variable, pareciera ahora que el comprador podría quedarse de brazos cruzados mientras se desarrolla la crisis en el periodo interino y hacer caso omiso de cualquier waiver que solicite el vendedor para autorizarlo a incumplir alguna de sus obligaciones de no hacer y así poder ejecutar medidas de salvaguarda. En ese caso, el vendedor puede ver si efectivamente la compañía se va en caída libre ante la inacción de dicho vendedor (contractualmente atado de manos). En caso de que, en efecto, el valor de la compañía caiga, es esperable que alguno de los supuestos MAC o MAE se configure. Con ello, el comprador se verá liberado de su obligación de adquirir la compañía. Es decir, el comprador no hace nada por liberar al vendedor de su dilema, no autoriza las medidas de salvaguarda para preservar el valor de la compañía; pero al mismo tiempo tampoco está asumiendo ningún riesgo de verse perjudicado por dicha pérdida de valor, ya que tiene una cláusula de salida que le permite darse la vuelta en caso de que efectivamente la compañía vaya mal. De esta forma, será el vendedor quien se quede con la compañía desvalorizada.

Así, en nuestro caso de estudio hay dos partes contractuales que pueden estar actuando de acuerdo con lo inicialmente pactado en su contrato y, de buena fe, encontrarse preocupadas por los intereses que cada una de ellas tiene en la operación. Sin embargo, ante la situación de crisis con las circunstancias que llevan a la compañía al límite es donde se agudizan estas diferencias.

\section{A MANERA DE EJEMPLO...}

Para ejemplificar este dilema, simplifiquemos aún más el supuesto y pensemos en un contrato de compraventa de una casa. Imaginemos que el vendedor se compromete frente al comprador a entregarle la casa dentro de un mes $y$, además, se obliga a no mojar los pisos de madera de dicho inmueble. Sin embargo, una semana antes de la entrega, durante el periodo interino del contrato de compraventa, la casa se empieza a incendiar. Entonces, el comprador se ve en el mismo dilema. Llevándolo un poco al absurdo, debe pensar qué hacer ante esa crisis: llamar a los bomberos e incumplir su obligación contractual de no mojar los pisos de madera de la casa, pero con la finalidad de intentar salvarla del incendio, o quedarse de brazos cruzados y cumplir a cabalidad con su obligación contractual, pero ver cómo la casa es consumida por el fuego. 
Con este ejemplo, se hace un poco más difícil de comprender el segundo supuesto y, en nuestra opinión, resulta evidente que la situación que pretende salvar la totalidad de la casa prevalece frete a savaguardar la obligación contractual.

\section{HERRAMIENTAS DISPONIBLES EN EL DERECHO CIVIL}

Pensando en las herramientas que nos otorga el Código Civil y poniéndonos en los zapatos del legislador, cuesta pensar que el mismo código que nos pide el saneamiento de los bienes, asegurar la habitabilidad de un bien inmueble, el deber de cuidado, las obligaciones de mitigación de daño y negociar de buena fe sea al mismo tiempo un código que ate de manos al comprador, imposibilitándolo de preservar el activo subyacente de un contrato de compraventa de acciones, al ser la compañía tan relevante para muchos stakeholders $y$, en consecuencia, valiosa en la sociedad. Lo cierto es que la situación descrita en el caso de estudio no tiene una solución predeterminada en nuestro ordenamiento, y debemos acudir a revisar las herramientas disponibles en el derecho civil para resolver el dilema.

Entonces, revisemos brevemente algunas de las herramientas contenidas en el Código Civil peruano, así como otras que podemos encontrar en el derecho comparado.

\section{- Cuantificación de daños: mitigación de daños}

En primer lugar, revisemos la figura de la obligación de mitigar daños, regulada en el artículo 1327 del Código Civil peruano. En ese supuesto, nos tenemos que situar en un momento en que ya ha ocurrido un incumplimiento y se ha producido un daño. Ahora, el problema aquí es que la figura de mitigación de daños que tenemos en el Código Civil no es aplicable al caso de estudio porque la figura de mitigación es una carga del acreedor de la obligación incumplida. En tal caso, precisamente el dilema del vendedor ocurre en un momento previo y parte del mencionado dilema es la evaluación de incumplir o no las obligaciones a su cargo en el contrato. Es cierto que su incumplimiento "mitigaría" los efectos de la crisis. Pero esa mitigación y ese perjuicio ocasionados por la crisis no han sido causados por el comprador, sino por un evento de fuerza mayor.

Por otro lado, también se podría argumentar que, por su parte, el comprador se halla en la obligación de "mitigar" los daños que se pudieran ocasionar por la crisis mediante el otorgamiento del waiver solicitado por el vendedor para autorizar su incumplimiento contractual y ejecutar las medidas de salvaguarda de la compañía. Sin embargo, esta situación tampoco cumple con los presupuestos requeridos por el Código Civil mencionados en el párrafo anterior.

Ello se encuentra muy ligado a la renegociación del contrato, porque efectivamente el waiver se va a otorgar a través de una modificación contractual, y aquí la llave del asunto es qué tanto yo puedo depender de la voluntad del comprador 
de que quiera otorgar el waiver, o exigirle que renegocie conmigo, porque en ese supuesto está por buena fe, en cierto modo, razonablemente obligado a renegociar y de una manera muy rápida.

- Frustración del propósito del contrato

Otra herramienta que no se halla en el Código Civil peruano, pero que encontramos en el derecho comparado es la figura de la frustración del contrato, incorporada en los Coronation cases y, además, actualmente adoptada en el Código Civil argentino. Esta figura presupone que existe un hecho no imputable a las partes por el cual se frustra todo el propósito que dichas partes inicialmente tenían para la celebración del contrato. Ello da lugar a la resolución del referido contrato.

En el caso de estudio no se produce una frustración del propósito del contrato porque, de nuevo, el hecho generador del dilema del vendedor se produce en un momento previo al que eventualmente generaría una frustración. Precisamente el vendedor quiere evitar que el propósito del contrato se vea frustrado por la pérdida de valor de la compañía; desea tomar las medidas de salvaguarda no solo para preservar el valor de la compañía, sino también para conservar el sentido de la operación de compraventa y que las partes no pierdan el interés en dicha contratación.

\section{- Excesiva onerosidad}

También se debe tener en cuenta la excesiva onerosidad del Código Civil peruano y el hardship del common law. Estas dos figuras han sido muy comentadas últimamente en el contexto de la COVID-19 precisamente porque son relevantes en contextos en los cuales el contrato deviene en un desequilibrio y existe un sobrecosto en la prestación en el marco de un contrato de ejecución continuada o diferida (como es el caso de estudio).

Este tampoco es nuestro caso de estudio porque la prestación no es el problema, sino que este radica en la complejidad de observar cómo está dada la asignación de riesgos en el periodo interino. En el momento en que surge el dilema del vendedor no se sabe en manos de quién van a quedarse las acciones $\mathrm{y}$, en consecuencia, el activo subyacente. Tampoco se posee certeza del valor de la compañía ni si dicho valor va a corresponder al precio pactado por las acciones. De nuevo, el dilema está destinado a determinar si se actúa para preservar dicho valor.

- Fuerza mayor

La última figura que vamos a repasar es la fuerza mayor, que se encuentra regulada en el artículo 1315 del Código Civil peruano. El caso fortuito y la fuerza mayor 
están contenidos en los supuestos de causas no imputables, que responden a la inejecución de obligaciones, junto con la actuación con diligencia ordinaria. Ya hemos conversado en varias oportunidades previas acerca de que, al menos en el Perú, la pandemia de la COVID-19 y el decreto que declara el estado de emergencia -y dispone la inmovilidad social obligatoria- son un supuesto de fuerza mayor para la mayoría de los casos que hemos revisado. Evidentemente, como bien se sabe, la fuerza mayor debe ser revisada caso por caso, de acuerdo con lo pactado en el contrato, las particularidades del contexto, la industria a la que pertenece la empresa contratante y las obligaciones que se encuentran pendientes de ejecución respecto a las cuales se alega fuerza mayor.

Más allá de este repaso, pensemos cómo se relaciona nuestro caso de estudio con la figura de la fuerza mayor. El Código Civil indica que la fuerza mayor es un evento irresistible, imprevisible, extraordinario que impide la ejecución de la obligación o determina su cumplimiento parcial, tardío o defectuoso. Ahora bien, ¿cómo aplicar esta figura a una obligación de no hacer como la descrita en nuestro caso de estudio?

\section{CONCLUSIONES: HERRAMIENTA CONTRACTUAL}

Como recomendación general ante este vacío o incertidumbre, tenemos siempre la posibilidad de hacer uso de la libertad contractual y prevenir estas situaciones regulando en nuestros contratos las consecuencias de un imprevisto similar en situaciones de crisis que se desaten durante el periodo interino. Este tema adquiere incluso mayor relevancia cuando recordamos que hace un tiempo se viene discutiendo la Ley del Control de Fusiones, cuya implementación va a ocasionar que los periodos interinos de las operaciones de M \& A (mergers and acquisitions) sean más prolongados.

La recomendación es realizar una excepción expresa a la obligación de llevar a la compañía de acuerdo con el curso ordinario, y facultar al vendedor para ejecutar actos que se encuentren destinados a preservar el valor de la compañía por causas que se relacionen con la pandemia, el coronavirus, el estado de emergencia y otros temas derivados, que razonablemente puedan destinarse a conservar el valor de la compañía, el negocio, las líneas de negocio y el desarrollo de las actividades de la compañía entendida como un negocio en marcha. 


\section{REFERENCIAS}

Código Civil del Perú. (1984). Recuperado de https://lpderecho.pe/codigo-civil-peruano -realmente-actualizado/

Decreto Supremo 044-2020-PCM, Decreto Supremo que declara Estado de Emergencia Nacional por las graves circunstancias que afectan la vida de la Nación a consecuencia del brote del COVID-19. (15 de marzo del 2020). Recuperado de https://cdn.www.gob.pe/uploads/document/file/566448/DS044-PCM_186 4948-2.pdf 